\title{
A CERÂMICA DE PUCARÁ NO PERU: MATERIALIDADE DA MEMÓRIA
}

\author{
DANIELLE ARAUJO ${ }^{1}$
}

UNILA

\begin{abstract}
RESUMO: Este artigo tem como objetivo tecer algumas considerações sobre memória e objetos pré-hispânicos ou, ainda, a memória dos objetos pré-hispânicos. A proposta foi elaborada a partir da pesquisa de campo, quando investiguei a relação dos objetos de cerâmica com a cosmologia andina. Minhas reflexões transitam entre os objetos pré-hispânicos e a imagem que eles projetam quando são "operacionalizados"(apropriados) pela indústria do turismo, em detrimento da relação que os artesãos produtores dos objetos estabelecem com os mesmos. Para os produtores, os objetos são a materialização da memória, representam e ao mesmo tempo agenciam práticas e concepções cosmológicas. A cultura material, no caso, a produção de objetos pré-hispânicos, narra um passado idealizado que é operacionalizado pela memória coletiva, ao passo que a agentiva é polissêmica, "significada" (inscrita) nas relações sociais. Essa perspectiva de análise não desconsidera as políticas de Estado e, sobretudo, de mercado e "comercialização do passado", tornando-o cada vez mais "exotizado" (exótico) e idealizado, tampouco esgota as inúmeras possibilidades de análises. No primeiro momento, apresentarei o Distrito de Pucará e alguns objetos que combinam e harmonizam a materialidade, a imagem, a história, a memória e o imaginário (do lugar, da comunidade). $\mathrm{Na}$ sequência, apresento as lógicas cosmológicas que animam os objetos e a convivialidade nos Andes. Posteriormente, concluo com uma análise transversal entre o que denomino de memória material e as imagens que alimentam a sua produção, analisando um objeto da cerâmica andina: o "torito de Pucará".
\end{abstract}

PALAVRAS-CHAVE: cultura material; cerâmica; memória.

ABSTRACT: This article aims to make some considerations about memory and pre-Hispanic objects, or the memory of pre-Hispanic objects. The proposal was drawn from the field research in which I investigated the relationship between potteries and the Andean cosmology. My reflections move between the pre-Hispanic objects and the image they project when "operationalized" (appropriated) by the tourism industry to the detriment of the relationship the craftsmen establish with the objects they produce. For the craftsmen, the objects are the materialization of memory, representing and exercising its agency towards practices and cosmological conceptions. The material culture, in this case the production of pre-Hispanic objects, recounts an idealized past that is operated by collective memory, while the agentive memory is polysemous, "signified" (inscribed) in social relations. This analytical perspective does not ignore state policies and, above all, market and "marketing of the past", making it increasingly "exoticized" (exotic) and idealized, nor exhaust the numerous possibilities of analysis. At first I introduce the Pucara District and some objects that combine and harmonize

\footnotetext{
${ }^{1}$ Doutora em Antropologia Social pela UFRGS e docente da Universidade Federal da Integração LatinoAmericana - UNILA. Trabalha com Cultura Material, Patrimônio imagem e Integração regional. E-mail: danielle.araujo@unila.edu.br.
}

Espaço Ameríndio, Porto Alegre, v. 8, n. 2, p. 152-167, jul./dez. 2014. 
the materiality, image, history, memory and the imagination (of place, community). Following, I present the cosmological logics that animate objects and conviviality in the Andes. Later, I conclude with a cross analysis between what I call material memory and the images that feed its production, analyzing an object of the Andean ceramics: the "torito de Pucará".

KEYWORDS: material culture; ceramics; memory.

\section{O Distrito de Pucará}

O distrito de Pucará está localizado no Departamento de Lampa, no Peru, onde se desenvolveu a cultura pukara. Assim como outros povos do chamado período pré-incaico, os Pukara não deixaram registro escrito da sua presença no continente americano. Por se tratar de uma civilização ágrafa, muitos dados estão dispersos nos monólitos, na arquitetura dos templos, na textilaria e nos objetos de cerâmica. Os estudos arqueológicos apontam que a civilização pukara existiu há aproximadamente 2000 a.C e 400 d.C e foi um dos maiores centros de produção de cerâmica, situado entre o lago Titicaca e Cuzco, no período Formativo Superior. A visão cronológica que procura explicar a dimensão do passado, presente neste trabalho, tem sido um discurso usual dos moradores do altiplano ao fazer referência à produção da cerâmica. Não se trata de uma visão somente evolucionista da história ou a adesão à concepção de tempo linear, mas uma explicação nativa que é importante para o grupo na tentativa de situar-se em relação a outras culturas produtoras de cerâmica.

A produção de objetos de cerâmica é uma das principais atividades econômicas do altiplano e, em Pucará, é a principal. Os objetos neste contexto são uma representação do tempo vivido. O que poucos observam, porém, é que, além de representantes do passado e de uma concepção de mundo atual, os objetos são testemunhas da passagem do tempo. Carregam na sua materialidade a memória individual e coletiva, ao passo que atualizam o presente.

De acordo com Manuel Ernesto Ramos Zambrano, historiador de Pucará, que publicou em 2004 o Enfoque Monográfico de Pucará, o Distrito tem origem em 1537, período da ocupação hispânica pelo 
invasor Diego de Almagro, tendo como base a cultura pukara. As pesquisas arqueológicas apontam a importância dos Pukara na evolução das técnicas de cerâmica andina.

Pucará dispõe de um conjunto arqueológico em uma extensão média de $4 \mathrm{~km}$, mantém uma série de edifícios de forma piramidal, geralmente superposta, com uma aparente função cerimonial. Estes edifícios estão formados por um jogo de muros, os andes, formando, no caso, a pirâmide Kalasaya.

A riqueza arqueológica de Pucará fez com que o Instituto Nacional de Cultura do Peru (INC) embargasse algumas obras sob o argumento de considerar a existência de outros centros cerimoniais soterrados. $\mathrm{O}$ centro artesanal ${ }^{2}$, construído há cinco anos, foi condenado à destruição por ter sido edificado em área imprópria.

Deste modo, o povoado de Pucará estaria assentado em área de extremo valor arqueológico e de riquezas outras. Moradores afirmam que o subsolo de Pucará contém ouro e pedras preciosas dos antepassados. A tradição local afirma que montanha de pedra, chamada de peñor San Caetano, está repleta de água e abriga um torito de ouro que dança nas madrugadas pucarenhas.

O pesquisador Rodolfo Sanches Garrafa investigou o apu Mallamanya, principal deidade do Distrito de San Juan de Totora província de Apurimac. Para os andinos, os apu são espíritos que habitam as montanhas - em quéchua, apu significa "senhor". Este termo é usado para se referir aos cerros e picos nevados onde pessoas de comunidades adjacentes fazem suas oferendas. De acordo com Rodolfo Sanches Garrafa, o Mallamanya é o principal apu da região, próxima a Cuzco, alcançando até $5.210 \mathrm{~m}$ sobre o nível do mar, cercado de montanhas menores.

Os apu são senhores dos homens, das plantas e dos animais. Concebido como um senhor com vontades próprias, os apu, por sua vez, também são semelhantes aos homens, com desejos e vontades boas e más. Para obter sua proteção, se faz necessário agradá-los com sacrifícios e oferendas. Mallamanya, para o povoado adjacente, representa o espírito mais poderoso, que protege as atividades agrícolas

\footnotetext{
${ }^{2}$ Trata-se de um grande prédio, que de fato destoa das demais construções do lugar, onde os artesãos receberiam cursos de aperfeiçoamento.
}

Espaço Ameríndio, Porto Alegre, v. 8, n. 2, p. 152-167, jul./dez. 2014. 
e pastoris. Este poderoso apu é refúgio de touros míticos, como o de Qochasaywas.

Como entidades dotadas de desejos e vaidades, os apu também possuem sexo e poderes relativos, sendo um mais poderoso que o outro.

Em Pucará, o apu San Caetano ou o majestoso peñor San Caetano, como dizem os pucarenhos, juntamente com o Puka Orcco ou Cerro Vermelho, formam o casal de apu de Pucará. San Caetano é o maior.

Como assinala Sanches Garrafa (2006, p. 221), o touro não tem origem na América, assim como o cavalo. Estes animais se tornaram substitutos de antigas figuras míticas. Na investigação sobre o apu Mallamanya, o pesquisador observou que as lagoas desempenham um papel fundamental - são currais de touros. No caso pesquisado, o apu Mallamanya foi refúgio dos touros, em razão da interferência do homem nas lagoas adjacentes.

Em Puca Orcco, o cerro menor, foram encontradas, em 1939, diversas litoesculturas atualmente expostas no Museu de Pucará. Dentreas peças encontradas, está a do degolador Hatun Nakaj, a estrela de felinos, a estrela antropomórfica feminina, a estrela de sete raios, o monólito antropomórfico, a estrela de suche, a estrela de caluyo, sapo e felinos litoesculpidos. Estas litoesculturas são facilmente copiadas pelos ceramistas que vendem as peças em miniatura na feira local.

Dentre as deidades cultuadas na cultura pukara, o felino ocupa lugar especial. Sua importância é observada não só nos Pukara e nos Chavin, mas em todo o território andino; é ele o representante do grande orgulho do povo andino: o lago Titicaca. Titicaca é uma palavra aymara que se decompõe em: titi- felino, puma, e kaka- peixe de grandes escamas sagradas. O Titicaca, ou lago sagrado, como é conhecido, é o lago navegável de maior altitude no mundo, abrangendo os territórios peruano e boliviano. A mais importante das ilhas é a do Sol no Peru e a da Lua, na Bolívia.

O felino, na figura do puma, foi o símbolo mais importante da civilização tiahuanaco, assim como de muitas culturas peruanas, dentre elas a chavin, como também de outras culturas americanas.

Ao Titicaca são atribuídas as insígnias de lago Sagrado, lago do Mistério.

Espaço Ameríndio, Porto Alegre, v. 8, n. 2, p. 152-167, jul./dez. 2014. 
Na versão lendária, o lago Titicaca foi o lugar de refúgio do sol e dos deuses, onde Noé, Nokke, e o povo escolhido permaneceram. Da arca de Noé, feita de pedra viva, saíram Manco Capac e Mama Oclo, os fundadores do mundo ${ }^{3}$. Advindos do lago Sagrado, os irmãos Manco Capac e Mama Oclo saíram para formar um grande povo. Eles caminharam vários dias com um bastão de ouro em busca de um lugar sagrado. Conta a lenda que neste lugar o bastão seria completamente cravado. Cuzco foi o lugar sagrado escolhido, onde o bastão foi cravado, formando o império dos Incas e a gloriosa cidade morada dos deuses; Machu Picchu.

A apresentação de Pucará e da cosmologia Andina mostram a relação entre a paisagem e os objetos de cerâmica, assim como a cosmovisão do lugar opera um imbricamento entre imagem, forma, memória, objetos e seus significados.

A Antropologia tem dedicado um interesse especial às relações "pessoa - objeto". Grant Mccraken (2007), ao observar as relações de consumo, diz-nos que o significado cultural se move entre o mundo culturalmente constituído para os bens de consumo e destes para o consumidor.

Os bens de consumo têm uma significância que vai além do seu valor comercial e utilitário; tais bens têm a condição de carregar e comunicar significado cultural. Para Mccraken, o significado do consumo dos bens culturais está em constante fluxo entre o mundo culturalmente constituído, o bem de consumo e o consumidor individual. Este autor observa que a localização original do significado cultural que reside nos bens de consumo é o mundo culturalmente constituído e percebido pela cultura, que, em última instância, determina como o bem será apreendido e assimilado. O significado pode ser caracterizado, basicamente, em termos de dois conceitos (planos essenciais): categorias culturais e princípios culturais. Das reflexões de Mccracken, considero importante destacar que, para este autor, um dos meios pelos quais a cultura se materializa é por intermédio dos objetos. Segundo Mccracken, "os objetos contribuem

\footnotetext{
${ }^{3}$ Durante a pesquisa, vivenciei, junto à população local, a encenação da saída de Manco Capac e Mama Oclo do Titicaca. Isto acontece no dia do aniversário de Puno. Uma grande festa, com inúmeras danças e fantasias acontece durante o dia. Manco Capac e Mama Oclo saem em cortejo pelas ruas de Puno até o colégio onde acontece o sacrifício da alpaca.
}

Espaço Ameríndio, Porto Alegre, v. 8, n. 2, p. 152-167, jul./dez. 2014. 
para a construção do mundo culturalmente constituído justamente porque registram de maneira vital e tangível um significado cultural que sem eles seria intangível" (MCCRACKEN, 2007, p. 106).

Com efeito, não é exagero dizer que os objetos têm uma função "performativa" (AUSTIN, 1963 e TAMBIAH, 1977 apud MCCRACKEN, 2007), na medida em que dão ao significado cultural uma concretude que do contrário ele não teria para o indivíduo e para a sociedade.

\section{Espaço e memória}

A (re)produção de objetos pré-hispânicos ocupa um lugar central no distrito de Pucará, embora o distrito também seja produtor de cerâmica utilitária e decorativa, consumida localmente.

No departamento de Puno e no departamento de Cuzco estão situados os centros turísticos mais importantes do Peru, respectivamente, o lago Titicaca e Machu Picchu. Os objetos protagonizam juntamente com a paisagem uma narrativa visual com significados particulares para os visitantes e os moradores do lugar. Os turistas que visitam a região se impressionam com a quantidade e variedade da produção artesanal, seja em cerâmica, textilaria, prata, dentre outras.

Aos turistas, o tempo passado é comercializado de forma exótica e sacralizada, fazendo com que o lugar se torne uma espécie de mina de ouro, onde o tempo passado parece "engolir" o presente. A passagem do tempo é utilizada para descobrir o passado que emerge supravalorizado na sua forma de apresentação e recepção.

A imagem emergida está em sintonia com um olhar que cria temporalidades e está em busca de imagens imemoriais; objetos soterrados, sítios arqueológicos que trazem à contemporaneidade uma imemorialidade enigmática. Gumbrecht (1998), diria que o movimento em direção ao passado é orientado pelo desejo de alcançar realidades passadas, pelo intento de falar com os mortos.

Bruno Latour (2007), em suas observações sobre temporalidades, afirma que a assimetria entre natureza e cultura se converte em uma assimetria entre passado e futuro. Os modernos têm a enfermidade da 
história, querem conservar tudo, pois acreditam que o passado passou por completo, quanto mais acumulam revoluções, tanto mais conservam, quanto mais capitalizam, mais põem em museus.

A destruição maníaca é "paga" (compensada) simetricamente com uma conservação maníaca que, sendo operada pela indústria do turismo, forja um passado cristalizado, uma memória mecânica e repetitiva que serve apenas para endossar um discurso interessado na venda de pacotes de turismo que são, na realidade, pacotes de retorno ao éden perdido.

Em detrimento do comércio do passado, sobrevive um presente pulsante. $O$ contato preliminar com a região do altiplano andino no Peru nos leva inicialmente a conceber a comercialização do passado como a única realidade onde a paisagem é narrada pela perspectiva mítica com interesses econômicos. Entretanto, a convivência com os artesãos apresenta uma lógica distinta, como diz Guimaraes Rosa, "o mundo do rio não é o mundo da ponte" (1976, p. 109).

O mundo da ponte é um mundo estagnado, enquanto o mundo do rio está em constante movimento em busca do mar. Essa metáfora se encaixa bem na realidade do tempo vivido ${ }^{4}$ (RICOUER, 2010) pelos ceramistas de Pucará. Tempo que não é expresso somente numa narrativa verbal, mas apresenta-se materializado nos objetos.

Os monólitos e a cerâmica contêm uma memória material construída e ressemantizada coletivamente. A memória, neste contexto, encontra-se fortemente enraizada em diferentes expressões materiais. Traços e detalhes, aparentemente insignificantes, separam milênios, trajetórias e concepções culturais. A materialização da memória nos objetos permite que eles conservem traços e, ao mesmo tempo, se modifiquem numa indissociabilidade entre material e simbólico, onde os ceramistas atribuem e incorporam substâncias e mensagens dos objetos. Logo, cada objeto guarda uma significância particular.

Os estudos de Maurice Halbawachs (2012) sobre a relação entre espaço e memória afirmam que o espaço deve ser pensado tendo como referência o ser humano, pois o espaço não é fixo, uma vez que está

\footnotetext{
${ }^{4}$ A consciência da narratividade (necessária) da História, reafirmada por Paul Ricoeur, apresenta implicações importantes, sendo a mais importante delas assegurar o retorno do vivido, da sensibilidade e da ação humana a uma historiografia que nos casos extremos parecia quase se abstrair do homem.
}

Espaço Ameríndio, Porto Alegre, v. 8, n. 2, p. 152-167, jul./dez. 2014. 
permeado pelas relações humanas. O território compreendido na sua condição de territorialidade mnemônica guarda e evoca uma memória agentiva que interfere na vida social. Paul Little utiliza o conceito de cosmografia para compreender e explicar como os grupos fazem uso do território:

a cosmografia de um grupo inclui seu regime de propriedade, os vínculos afetivos que mantêm com seu território específico, a história da sua ocupação guardada na memória coletiva, o uso social que dá ao território e as formas de defesa dele (LITTLE, 2002, p. 03).

Citando Casimir, o autor explica que a territorialidade é uma força latente em qualquer grupo cuja manifestação explícita depende de contingências históricas.

\section{Objeto, memória e agência}

Falar sobre a condição dos objetos enquanto veículos de significância cultural é um dos pontos centrais das reflexões de Grant Mccraken; porém, uma questão relevante da relação entre objetos e memória reside na compreensão de como os objetos, no caso os préhispânicos, "carregam" essa significação cultural, ou seja, como eles agenciam.

No que concerne à compreensão dos objetos, a interpretação antropológica tem uma negligência considerável. Alfred Gell (1992) afirmou que a Antropologia é essencialmente antiarte, propondo, assim, uma nova abordagem aos estudos sobre os objetos. Gell observa que as abordagens que privilegiam os aspectos estéticos dos objetos não estão propondo uma Antropologia da Arte. A laboriosidade de determinadas culturas na produção de esculturas, onde o virtuosismo técnico é expressivo, não produz objetos com pretensão de que estes sejam concebidos como belo ou para fins decorativos.

Alfred Gell (1992) nos diz que o importante para a análise antropológica é a agência, e a eficácia simbólica. Logo, a arte se aproxima mais da magia, pois em ambas há um encantamento

Espaço Ameríndio, Porto Alegre, v. 8, n. 2, p. 152-167, jul./dez. 2014. 
tecnológico, algo que apreende profundamente o espectador, gerando neste uma ação pela agência do objeto. Em Gell, os objetos não veiculam mensagens simbólicas a serem decodificadas, mas possuem uma agência que promove uma ação no grupo onde é produzido. Ao afirmar que os objetos na Antropologia não podem ser concebidos pela sua estética, mas pela agência, Gell contempla a capacidade da arte em transformar, e não em informar o mundo.

Gell baseia-se nas proposições de Peirce. Transpõe alguns conceitos na tentativa de esboçar uma teoria da arte que compreenda o papel dos objetos e sua condição de agenciar relações sociais. Ele compreende o index como o resultado e/ou o instrumento da agência social. O índice é o objeto integrado num sistema de interação do artista ou artesão com o destinatário do objeto (recipient); o protótipo e as entidades, concebidas por uma operação de abdução. Nesta relação, o paciente, observador, torna-se agente pela ação que recebe.

O artista é responsável pela existência e pelas características do index, produzindo uma iconografia, o signo, que, portanto, não é arbitrário; o recipient ou destinatário do objeto é aquele em relação ao qual os indexes exercem a agência, ou sofrem a agência. Cada termo se torna agente ou paciente num sistema de interação, no qual a dinâmica se funda na intencionalidade; as posições não estão fixas. $O$ objeto ou índice é um ponto central da relação entre o agente e o paciente, uma relação fundada sobre o ato de ver e o ato de ser olhado. A posição de observador é integrada à estrutura da agência.

A fascinação pelos objetos de arte, presente em muitos contextos, ilustra como o objeto aparece na forma de agente, provocando no espectador uma espécie de emoção que Gell chama de captivation.

Assim como Els Lagrou, observo que as inferências de Gell trazem ao debate da Antropologia da Arte algumas reflexões importantes. A mais relevante é o fato de colocar as relações entre humanos e não humanos (objetos e imagens) de modo equiparado. Entretanto, a recusa do autor em negar a condição dos objetos em transmitir, vincular aspectos do grupo onde é produzido, reduz o caráter elucidativo proposto pela sua análise.

Para Lagrou (2007), Gell faz um uso restritivo da ideia de sentido, pois autores como Geertz e Levi-Strauss, ao salientarem os aspectos

Espaço Ameríndio, Porto Alegre, v. 8, n. 2, p. 152-167, jul./dez. 2014. 
simbólicos ou semióticos da arte, não desconsideram a ação do simbolismo e sua capacidade transformadora. A crítica de Gell, entretanto, parece incidir sobre a busca de entender o simbolismo aliado a aspectos como o inconsciente e a linguagem.

A significação e o valor atribuído à peça têm importância para o autor. Isto pode ser verificado na relação com o index, que precisa ser interpretado para que os artefatos possam ter agência. A agência dos objetos, sua ação/transformação, acontece em decorrência da capacidade de simbolizar, e tal capacidade só é possível devido à memória que interliga temporalidades, trazendo uma espécie de passado atualizado. A agência que os objetos provocam é resultante de experiências diárias; experimentos coletivos e individuais onde os artistas sofrem inferências. O êxito ou fracasso na produção dos objetos, isto é, o processo de feitura demonstra a satisfação ou insatisfação dos deuses. A memória enquanto reconstrução psíquica e seletiva opera na seleção e na significância expressa na forma e nos objetos.

\section{Um objeto particular: O Torito de Pucará}

O torito de Pucará é a peça de cerâmica mais produzida e uma das mais comercializadas. O torito não é um objeto pré-hispânico, pois sua forma e significado não está delimitado a uma "cultura" anterior ao período da colonização. Como foi citado, o touro não é um animal originário das Américas; entretanto, esse objeto cruza temporalidades, interliga concepções de mundo e informa sobre a relação entre humanos e extra-humanos. O pesquisador Juan Palao foi o primeiro dos meus interlocutores a afirmar que o torito, no passado, teve uso ritual. Segundo o pesquisador, ele era sepultado no terreno, antes da casa ser construída. A tradição de enterrar o torito segue a lógica dos pagos (sacrifícios) à Pachamama, ritual muito presente em todo altiplano. Os pagos a Santa terra são formas de oferecer/pagar, enterrando oferendas, que são formas de pagamento e ao mesmo tempo pedido, segundo a teoria da reciprocidade de Mauss. Palao afirma que, nos últimos anos, o uso ritual do torito tem dado lugar ao uso decorativo; 
antes o torito era preenchido com coca, álcool e chincha, o que explicaria a presença de um orifício na região lombar.

A maior festa do distrito acontece no período do Natal: a corrida de touros, que resulta na morte dos touros em praça pública. Seja do ponto de vista mitológico ou festivo, é notória a influência desse animal nos países latino-americanos, onde é símbolo de força e fertilidade. Os moradores afirmam que o torito de Pucará nasce de comemorações rituais para a procriação do gado. Na entrevista, segue a fala do Alcalde e dos ceramistas,

Como es del conocimiento de muchos el torito de Pucará nace gracias a una fiesta de la santísima trinidad donde se empezaba a darle al toro un homenaje por la fuerza que desde entonces desempeñaban cuando araban y desde entonces los agricultores los agarraban los toros y los adornaban, pintaban el cuerpo e así se plasma toda esa tradición en la cerámica y que hoy es difundido a nivel mundial nuestro torito de Pucará (LEONARDO, ALCALDE DE PUCARÁ).

¿Qué significa el torito de Pucará? Antiguamente nuestros abuelos, todavía, hacen una fiesta la cual era un carnaval hacia la marcación de su ganado, era una gran fiesta. Porque el torito de Pucará les daba ingreso económico por eso hacían una fiesta grande bailaban pintaban a los animales todos acustavam porque era una zona ganadera. Ahora nuestro torito de Pucará están mas valorados porque es conocido mundialmente entonces trabajamos mas.

El torito de Pucará también significa fuerza y también hacían la abertura servía como vasija para beber su chicha (ALICIA FRISANCHO, CERAMISTA).

$\mathrm{Na}$ pesquisa de campo, houve variações do descrito, mas em todos os relatos aparece a cerimônia de marcação do gado ${ }^{5}$ como rito originário do torito de Pucará.

Este objeto carrega em si elementos individuais e coletivos do grupo onde é originado. No caso do torito de Pucará, os traços de força e poder, são alvos de poucas variações, o mesmo não podendo ser dito dos desenhos, pinturas feitas sobre o torito, os quais variam. A forma, e

\footnotetext{
${ }^{5}$ Cerimônia onde o gado era bento para uma próspera reprodução.
}

Espaço Ameríndio, Porto Alegre, v. 8, n. 2, p. 152-167, jul./dez. 2014. 
com ela saliências e orifícios, permanecem, deixando explícito o uso ritual do objeto e a permanência de um estilo.

Em Gell (1998), a discussão sobre o estilo assume outros caminhos. Ele rejeita a análise que relaciona estilo a uma capacidade psíquica individual. $\mathrm{O}$ foco do autor está nas formas tradicionais de arte, produções coletivas ligadas a parâmetros culturais onde, supostamente, a inovação é algo restrito, porém não inexistente.

No caso do torito, observo que o tamanho do orifício no dorso do animal é algo saliente, o que atesta o uso ritual. O afunilamento do orifício parece ser resultante da redução do uso ritual ou da mudança de função, quando este passa a ser usado como vaso de flores, por exemplo. As alterações da forma e do estilo estão relacionadas ao papel que o objeto desempenha no meio social. Observando que o mesmo objeto com formas e estilos iguais servem a diferentes propósitos. De todo modo é válido observar o motivo de destaque dessa peça em detrimento a outros objetos.

O torito de Pucará, conhecido nacional e internacionalmente, não está inserido no meio social por vontade e/ou decisões políticas nem por imposição, nem mesmo por uma atividade consciente e deliberada dos indivíduos. Apesar do touro ser de origem hispânica, ele se inseriu decisivamente nos Andes e assim não teria acontecido se não houvesse um correspondente direto: o felino. O torito como correspondente direto é chave central para compreender a prevalência desse objeto, pois ele, como diria Goncalves (2004), ressoa na comunidade.

A relação direta entre o felino e o torito é feita por muitos ceramistas de Pucará. Tal relação nasce principalmente da leitura das formas das montanhas quando estes afirmam que o peñor San Caetano ${ }^{6}$ ora se assemelha a um felino, ora a um torito, numa constante sobreposição de imagens na construção narrativa. Neste sentido, o torito insere-se no que Latour (2007) denomina de híbridos, "seres politemporais".

Fora a semelhança formal, estão as capacidades psíquicas valoradas pelos ceramistas. O torito é símbolo de força, fartura e potência sexual reprodutiva. Identificar-se com este animal significa

\footnotetext{
${ }^{6}$ Peñor San Caetano é um apu, que significa "senhor" em quéchua. Trata-se de uma montanha sagrada, a maior da região.
}

Espaço Ameríndio, Porto Alegre, v. 8, n. 2, p. 152-167, jul./dez. 2014. 
também corporificar estes elementos, tornar-se touro, incorporar suas substâncias. Os aspectos de imponência e força expressos nos toritos pelos ceramistas é uma forma de projetar no meio social elementos valorados internamente. Daí a afirmativa enfática: "Pucará es la cuna artesanal; la mejor cerâmica es de acá".

A particularidade dos ceramistas, imprimindo, cada um ao seu modo, traços, linhas e adereços ao torito, apresenta-nos a diversidade dos toritos. A técnica utilizada também é importante, no caso dos objetos, para explicar mudanças e permanências. Entretanto, os objetos, enquanto seres que transcendem sua condição material sem negá-la, são significados pelos fios da memória coletiva, transformando-se e ressignificando-se pela experiência de cada ceramista. O objeto é retomado no seu passado na sua importância remota e é atualizado no presente por uma memória materializada que agencia práticas e concepções; tal memória está presente em todas as etapas, inclusive durante a produção do objeto, onde o contato com o visível e o invisível é intensa. Este objeto remonta, pela sua forma de feitura, matériaprima, traços e adereços da cosmologia pucarenha, saberes partilhados, assim como segredos velados. O torito é um eterno vir-a-ser, não será o que é, mas levará ao futuro o que está.

O trabalho de Van Velthem sobre a estética wayana atesta que "os objetos transmitem conhecimentos acerca da imagem que seus produtores fazem de si mesmos e referendam formas diversas de veicular tal imagem" (VAN VELTHEM, 2004, p. 52-53). Quando diretamente vinculadas aos conceitos cosmológicos, as artes indígenas convertem-se antes em prismas que refletem as concepções acerca da composição do universo e dos componentes que o povoam, sobretudo dos que estão alijados da sociedade, os mortos, os inimigos, os animais, os sobrenaturais (VAN VELTHEM, 2004).

O torito de Pucará, objeto artesanal, nasce da marcação do gado, uma prática ritual transmutada em objeto. Não se trata de perceber esta relação numa lógica objetal em que o torito seria simplesmente a expressão de um momento ritual, pelo contrário, o dito objeto é incorporado de entidades e substâncias, o torito nestes termos não é apenas a representação de um ritual, pois, na perspectiva dos seus

Espaço Ameríndio, Porto Alegre, v. 8, n. 2, p. 152-167, jul./dez. 2014. 
produtores, ele passa a ter uma agência social e cosmológica quando enterrado ou colocado no telhado das casas.

Por se tratar de um objeto que atravessa temporalidades e espacialidades, o torito oscila entre tempos, compartilhando, com os moradores do Distrito, usuários e consumidores, momentos ordinários e/ou rituais da vida humana e extra-humana. Trata-se de um objeto animado que transmite força e segurança por intermédio de sua matéria prima, formas, linhas e desenhos, corporificando entidades e substâncias. Ganha vida no imaginário, quando dança nas madrugadas revestido de ouro ${ }^{7}$, um objeto nascido de uma cerimônia que vive na forma de artefato material, tornando-se chave para a compreensão da vida humana e extra-humana do local onde é produzido.

Sobre a relação dos objetos com a narrativa mítica, Van Vetlhem assinala que a ordem cósmica é considerada como parte da ordem social, onde a estética está ligada ao universo cosmológico, cuja lógica é partilhada pelo produtor e pelo grupo receptor ou espectador. O objeto, deste modo, é um mediador entre domínios distintos, aproximando o mundo animado do inanimado.

O torito de Pucará é o patrimônio atualizado e compartilhado, construído e apropriado pelos moradores do Distrito. Para este objeto, ícone, o tempo passado e futuro inexistem, uma vez que nele gravitam temporalidades que se mantêm e ao mesmo tempo se projetam. A venda do objeto implica comercializar também as estórias ou as lendas que existem ou são criadas sobre ele; entretanto, nem sempre identificadas.

A entrada do torito num circuito comercial, juntamente com suas crenças e cosmovisão, não pode ser compreendida apenas pela lógica da perda, redução do valor simbólico, dentre outras análises que buscam o autêntico das coisas, pois o autêntico é passível de reinvenções, criações e incessantes ressemantizações. Esses objetos, distribuídos nas suas formas e estórias, multiplicam e criam, de modo particular, novos significados. A diversidade do torito é explicada não só pela necessidade dos ceramistas em colocar no mercado objetos diversos, mas porque a vida é constituída de abandonos e apegos. A

\footnotetext{
${ }^{7}$ De acordo com alguns artesãos, o peñor San Caetano guarda um torito de ouro que dança nas madrugadas pucarenhas.
}

Espaço Ameríndio, Porto Alegre, v. 8, n. 2, p. 152-167, jul./dez. 2014. 
DANIELLE ARAUJO - A cerâmica de Pucará no Peru

feitura das peças acompanha as vicissitudes do viver. Logo, o torito, num plano técnico, psíquico e histórico-cultural, condensa esses vários elementos.

\section{Referênciasbibliográficas}

GONÇALVES, José R. S. Ressonância, materialidade e subjetividade: as culturas como patrimônios. Horizontes Antropológicos, Porto Alegre, v. 10, n. 22, p. 15-36, 2004.

GEERTZ, Clifford. A interpretação das culturas. Rio de Janeiro: LTC, 1989.

GELL, Alfred. The technology of enchantment and the enchantment of technology. In: COOTE, J.; SHELton, A. (Org.). Anthropology, Art and Aesthetics. Oxford: Clarendon Press, 1998. p. 40-66.

GREENBLATT, Stephen. Ressonance and wonder. In: KARP, Ivan; STEVEN, Lavine (Org.). Exhibiting cultures: the poetics and politics of museums display. Washigton: Smithosonian Institution Press, 1991. p. 25-41.

GUMBRECHT, Hans Ulrich. Modernização dos Sentidos. São Paulo: Ed. 34, 1998.

LAGROU, Elsje Maria. A fluidez da forma: arte, alteridade e agência em uma Sociedade Amazônica (Kaxinawma, Acre). Rio de Janeiro: Topbooks, 2007.

LATOUR, Bruno. Nunca fuimos modernos: ensayo de antropologia simétrica. Buenos Aires: Siglo XXI, 2007.

LÉVI-STRAUSS, Claude. O Pensamento Selvagem. São Paulo: Edusp, 1962.

LITTLE, Paul E. Territórios Sociais e Povos Tradicionais no Brasil: Por uma Antropologia da Territorialidade. Brasília: UnB, 2002.

MCCRACKEN, Grant. Vestuário como linguagem: uma lição objetiva no estudo das propriedades expressivas da cultura material. In: Cultura e Consumo: novas abordagens ao caráter simbólico dos bens e das atividades de consumo. Rio de Janeiro: MAUAD, 2003. p. 83-98.

MCCRACKEN, Grant. Cultura e consumo: uma explicação teórica da estrutura e do movimento do significado cultural dos bens de consumo. RAE, São Paulo, v. 47, n. 1, p. 99-115, 2007.

Espaço Ameríndio, Porto Alegre, v. 8, n. 2, p. 152-167, jul./dez. 2014. 
DANIELLE ARAUJO - A cerâmica de Pucará no Peru

RICOEUR, Paul. Tempo e narrativa: a tríplice mimese. In: narrativa. Campinas, Papirus, 2010. p. 85-131. Tomo I.

Tempo e

ROSA, Joao Guimarães. Tutameia. Rio de Janeiro: Jose Olímpio, 1976.

SÁNCHEZ GARRAFA, Rodolfo. Apus de los Cuatro Suyos: construcción del mundo en los ciclos mitológicos de las deidades montaña. 2006. $372 \mathrm{f}$. Tese (Doutorado em Antropologia). Universidad Nacional Mayor de San Marcos, Lima, Perú. [2006]. Disponível em: http://www.cybertesis.edu.pe/sisbib/2006/sanchez_gr/html/indexframes.html. Acesso em: 17 jan. 2009.

VAN VELTHEM, Lúcia. O belo é fera: a estética da predação e da produção entre os Wayana. Lisboa: Assírio \& Alvim, 2003.

Objetos etnográficos, coleções e Museus. In: MOREIRA, Eliana et al (Org.). Propriedade Intelectual e patrimônio cultural: proteção dos conhecimentos e das expressões tradicionais culturais. Belém: Biblioteca do CESUPA, 2004.

ZAMBRANO, Manuel Ernesto Ramos. Enfoque monográfico de Púcara. Puno: Universidad Nacional del Altiplano de Puno, 2004.

Espaço Ameríndio, Porto Alegre, v. 8, n. 2, p. 152-167, jul./dez. 2014. 